\title{
Operational ocean forecasting in the Eastern Mediterranean: implementation and evaluation
}

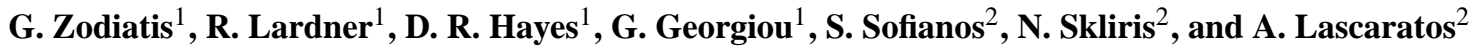 \\ ${ }^{1}$ Oceanography Centre, University of Cyprus, P.O. Box 20537, 1678 Nicosia, Cyprus \\ ${ }^{2}$ Applied Physics Dept., Ocean Physics Modelling Group, University of Athens, Athen, Greece
}

Received: 28 March 2006 - Published in Ocean Sci. Discuss.: 8 June 2006

Revised: 6 September 2006 - Accepted: 11 December 2007 - Published: 4 February 2008

\begin{abstract}
The Cyprus Coastal Ocean Forecasting and Observing System (CYCOFOS) has been producing operational flow forecasts of the northeastern Levantine Basin since 2002 and has been substantially improved in 2005. CYCOFOS uses the POM flow model, and recently, within the frame of the MFSTEP project, the flow model was upgraded to use the hourly SKIRON atmospheric forcing, and its resolution was increased from $2.5 \mathrm{~km}$ to $1.8 \mathrm{~km}$. The CYCOFOS model is now nested in the ALERMO regional model from the University of Athens, which is nested within the MFS basin model. The Variational Initialization and FOrcing Platform (VIFOP) has been implemented to reduce the numerical transient processes following initialization. Moreover, a five-day forecast is repeated every day, providing more detailed and more accurate information. Forecast results are posted on the web page http://www.oceanography.ucy.ac.cy/cycofos. The new, daily, high-resolution forecasts agree well with the ALERMO regional model. The agreement is better and results more reasonable when VIFOP is used. Active and slave experiments suggest that a four-week active period produces realistic results with more small-scale features. For runs in September 2004, biases with remote sensing sea surface temperature are less than $0.6^{\circ} \mathrm{C}$ with similar expressions of the flow field present in both. Remotely-observed coastal upwelling south of Cyprus and advection of cool water from the Rhodes Gyre to the southern shores of Cyprus are also modeled. In situ observed hydrographic data from south of Cyprus are similar to the corresponding forecast fields. Both indicate the relatively fresh subsurface Atlantic Water and a near-surface anticyclone south of Cyprus for August/September of 2004 and September 2005. Plans for further model improvement include assimilation of observed XBT temperature profiles, CTD profiles from drifters and gliders, and CT data from the CYCOFOS ocean observatory.
\end{abstract}

Correspondence to: D. R. Hayes

(dhayes@ucy.ac.cy)

\section{Introduction}

Forecasting seawater movements and properties is of importance in understanding the effects of human activities on the marine environment as well as the effect of marine conditions on human operations in the sea. Flow modelling is considered a useful operational tool for decision-making in case of marine accidents. Some examples where operational forecasting is vital include search and rescue, oil spill fate modelling, and dispersion of pollutants. The practical real-time benefits of operational oceanography also bring improved understanding of environmental conditions and change at many levels. These operational activities imply a close attention to marine conditions on a daily basis over a period of years and from basin scales down to coastal scales.

The Cyprus Coastal Ocean Model (CYCOM) is one of the coastal/subregional models of the Mediterranean Forecasting System (MFS) project (Pinardi et al., 2003), for high resolution flow simulations in the Cyprus and the NE Levantine basins. CYCOM has been running continuously since 2002 in various configurations. In this study, it is nested within the Aegean Levantine Eddy Resolving Model (ALERMO), which covers the whole Eastern portion of the Mediterranean Sea. In this paper the performance of CYCOFOS is investigated by examining the effects of downscaling and initializing from the regional model and the degree of agreement of the forecasts with remote-sensing and in situ observations. The effect of downscaling is investigated for October 2005, during the period of transition between the bilinear interpolation and the variational method of initialization. The effect of initializing at weekly or monthly intervals is examined for 2 periods: September 2004 and January 2005, when special "active- slave" runs were conducted. The agreement of forecasts with remote-sensing takes place also for September 2004 and January 2005. Comparisons with in situ data are made first for August 2004, January 2005 (active-slave runs), then September 2005 and July 2006 (operational forecasts).

Published by Copernicus Publications on behalf of the European Geosciences Union. 


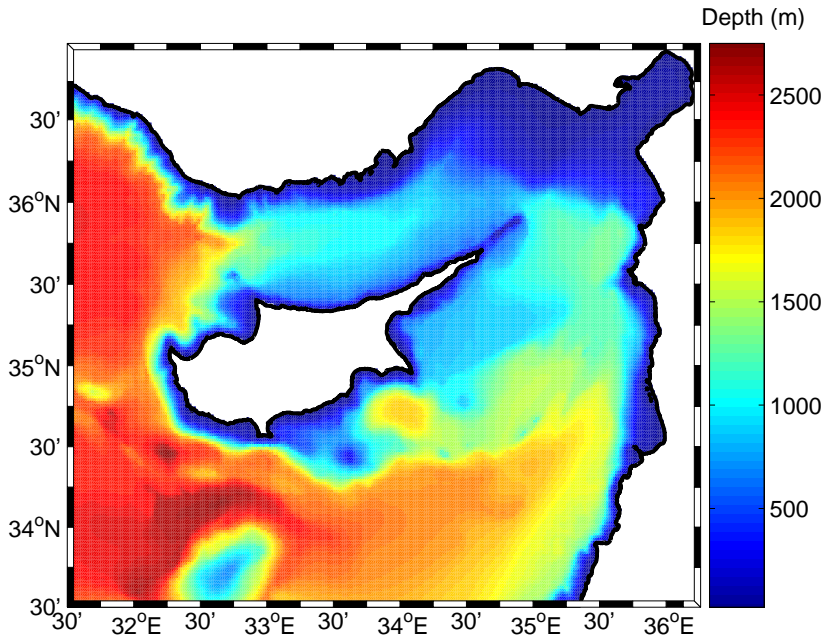

Fig. 1. Bathymetry and domain of CYCOM.

The known features of the general circulation near Cyprus as well as the climatological output for CYCOM are discussed by Zodiatis et al. (2003). In summary, Cyprus has no significant river discharge, very narrow coastal areas with steep topographic gradients for shelf breaks and a shoreline exposed to the open sea. The coastal/shelf areas of the Levantine Basin are dominated by the mesoscale flow phenomena of the neighboring deep regions, such as the jet of Atlantic Water that meanders south of Cyprus, the Asia Minor Current, the Rhodes Gyre, and various eddies that can persist south of Cyprus for months. Storm surges are not important because of only moderate storm intensity, small tidal range (less than $0.3 \mathrm{~m}$ ), and generally steep coastlines. Only the near-surface layers are affected by persistent westerly winds, which result in an upwelling feature on the southern or southwestern coast of Cyprus.

\section{Methods and model descriptions}

Both CYCOM and ALERMO use numerical schemes that are modified versions of POM (the Princeton Ocean Model). The POM model has been widely used both within the framework of the MFS and elsewhere to simulate the flows in both regional and subregional sea areas of the Mediterranean Sea. POM has been extensively described in the literature (Blumberg and Mellor, 1987; Lascaratos and Nittis, 1998; Zavatarelli and Mellor, 1995). The POM model is a primitive equation, 3-D ocean circulation model based on the full nonlinear equations of momentum and mass conservation and their depth-averaged forms. The model comprises a bottomfollowing sigma coordinate system, a free surface, and split mode time steps. At each time-step, the surface elevation and vertically integrated mass transports (that is, the barotropic mode) are computed from the depth-averaged equations by an explicit leapfrog scheme. The vertical structure of the current (baroclinic mode) is obtained from the horizontal momentum equations with a longer time step (Lardner and Cekirge, 1998). Advancing the baroclinic mode is computationally much more demanding and the use of a longer time step for it makes the overall computational scheme quite efficient. All sub-grid-scale phenomena are considered as mixing processes by introducing separate horizontal and vertical mixing terms. The horizontal viscosity and diffusion terms are evaluated using the Smagorinsky (1963) horizontal diffusion formulation while the vertical mixing coefficients for momentum and tracers are computed according to the Mellor-Yamada 2.5 turbulence closure scheme (Mellor and Yamada, 1982). Heat and salinity transport sub-models are included. Potential temperature, salinity, velocity and surface elevation, are the prognostic variables of the model.

\subsection{Cyprus Coastal Model (CYCOM)}

The domain of CYCOM (Fig. 1) is bounded by coastline on the north and east (maximum latitude of $36^{\circ} 55^{\prime} \mathrm{N}$ and maximum longitude of $36^{\circ} 13^{\prime} \mathrm{E}$ ). The open boundary to the south is the $33^{\circ} 30^{\prime} \mathrm{N}$ latitude line, and the open boundary to the west is the $31^{\circ} 30^{\prime} \mathrm{E}$ meridian. Horizontal Cartesian co-ordinates are in the Mercator projection with an Arakawa $\mathrm{C}$-grid, and the resolution is uniform at one minute (approximately $1.8 \mathrm{~km}$ ) for a total of $284 \times 206$ horizontal grid points. The grid-spacing is sufficiently small to resolve steep bathymetry in the region as well as features with internal Rossby radius length scales $(10-15 \mathrm{~km})$. In the vertical, a non-uniform grid of 25 sigma layers was used with exponentially decreasing spacing near the surface and sea bed to provide finer resolution of the surface and bed layers. The bottom topography is based on the $1^{\prime} \times 1^{\prime}$ U.S. Navy Digital Bathymetric Database. The minimum depth is $20 \mathrm{~m}$. The equations used in CYCOM are described in Zodiatis et al. (2003).

In order to initialize CYCOM, the ALERMO data are downscaled from its lower resolution, larger domain using VIFOP (Variational Initialization and Forcing Optimization Platform). The Variational Initialization technique (Auclair et al., 2000a, b) analyzes the outputs of the regional scale circulation model used as initial field of high resolution ocean models to reduce the amplitude of the numerical transient processes following the initialization. The VIFOP package was successfully implemented and configured in the CYCOM model as in ALERMO, which had first used VIFOP for downscaling from the Mediterranean basin model. Previously, bilinear interpolation in the horizontal was used. (No interpolation is necessary in the vertical since the same sigma layers and bathymetry are used.) The procedure for nesting within ALERMO (resolution of $3 \mathrm{~km}$ ) is identical to that described by Zodiatis et al. (2003). A passive, one way interaction is used (Spall and Holland, 1991), where the nesting provides for information to be passed along the open boundaries from the ALERMO coarse grid to the CYCOM highresolution grid model. 

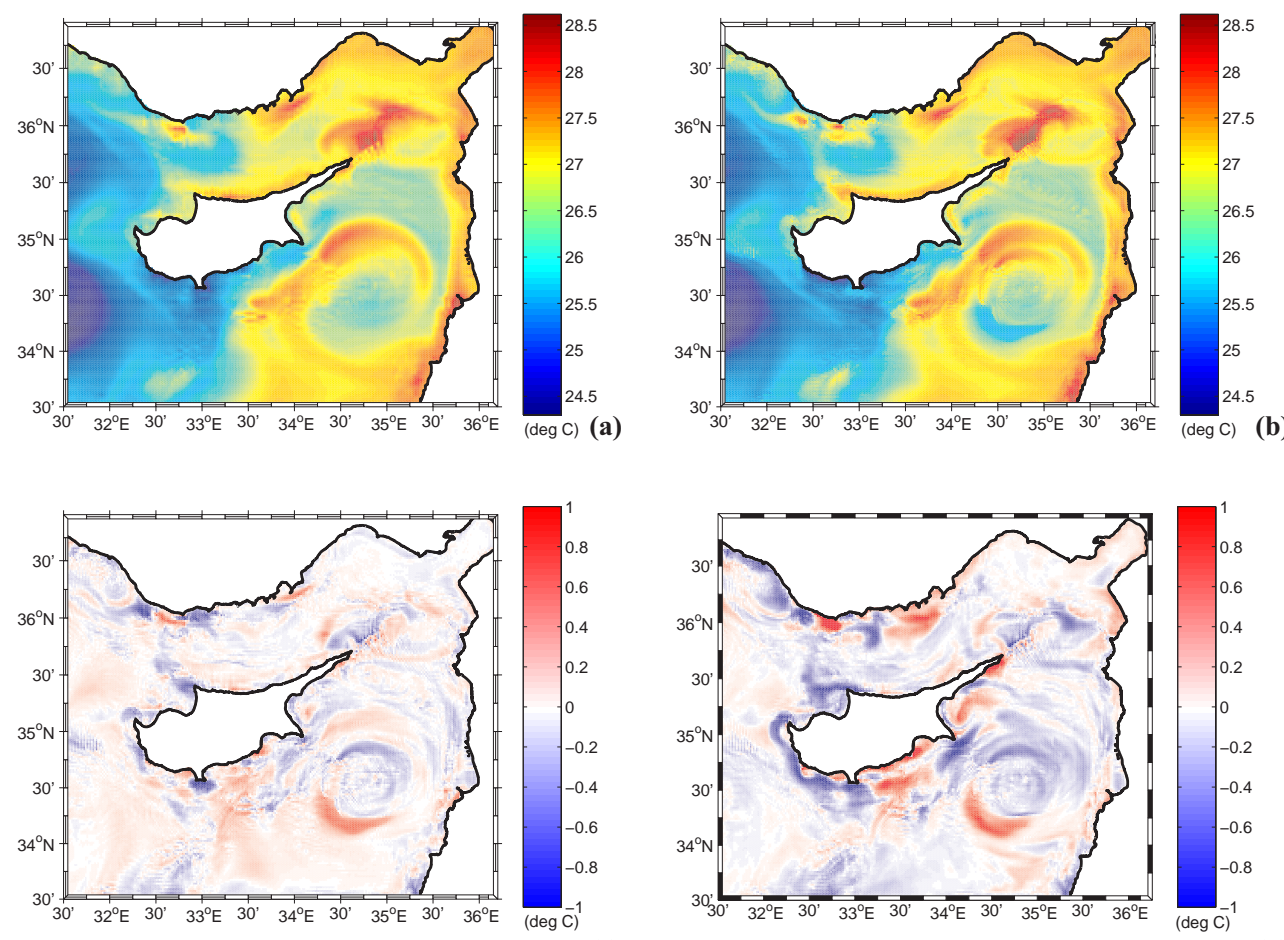

(c)

(d)

Fig. 2. Sea surface temperature for operational mode forecasts from (a) ALERMO (b) CYCOM, using the VIFOP method of initialization. (c) The temperature difference field of (a) and (b). (d). The same as (c) but using the CYCOM forecast that did not use VIFOP. The output fields are 24-h averages on 2 October 2005, which was the fourth day of the forecast.

Surface and bottom boundary conditions are applied as described in Zodiatis et al. (2003). Surface boundary forcing is provided by the SKIRON 5-day forecast (Kallos et al., 1997). The high-resolution $\left(0.1^{\circ}\right)$ and high-frequency (hourly) forecast is available daily and starts at midnight. It provides 10-m wind speed, 2-m air temperature and relative humidity, the precipitation rate, the shortwave radiative gain by the ocean and the infrared atmospheric radiation reaching the sea surface. These daily atmospheric forecasts are used for each new ocean forecast using the bulk flux formulation. Downward shortwave and longwave radiation are used directly from SKIRON, while heat loss terms are calculated from SKIRON-provided parameters. Sensible and latent heat are calculated from Budyko (1963), longwave loss is calculated from Bignami (1995). Evaporation is also calculated from Budyko (1963) and combined with SKIRON-provided precipitation for surface salinity flux. Surface momentum fluxes are calculated using the computed drag coefficient of Hellerman and Rosenstein (1983). There is no relaxation of surface fields.

The daily average fields required by the MFSTEP project for all partners are posted on the web site: http://www.oceanography.ucy.ac.cy/cycofos. Five subregions can be viewed online and forecast data can be downloaded for user-visualization using the Visual Interface of Oceanographic Data, VIOD, or for use in the oil spill model,

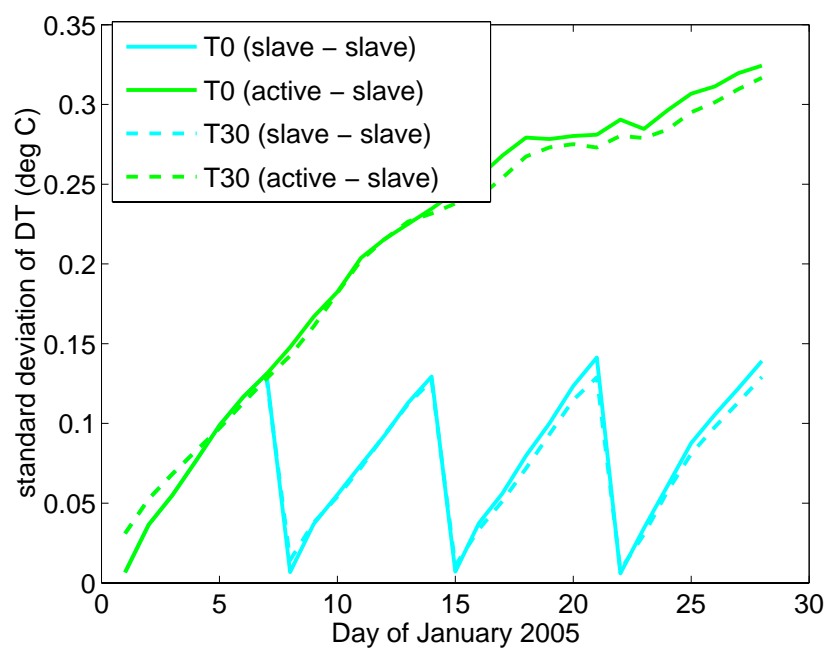

Fig. 3. Root-mean-square differences of temperature between various runs throughout the January 2005 experiment. Solid lines are for surface temperature, dotted are for $30 \mathrm{~m}$. Cyan line is for ALERMO slave minus CYCOM slave. Green line is for ALERMO active minus CYCOM active.

MEDSLIK. Both of these programs are freely available. In addition, 6-h averages are also now available. 

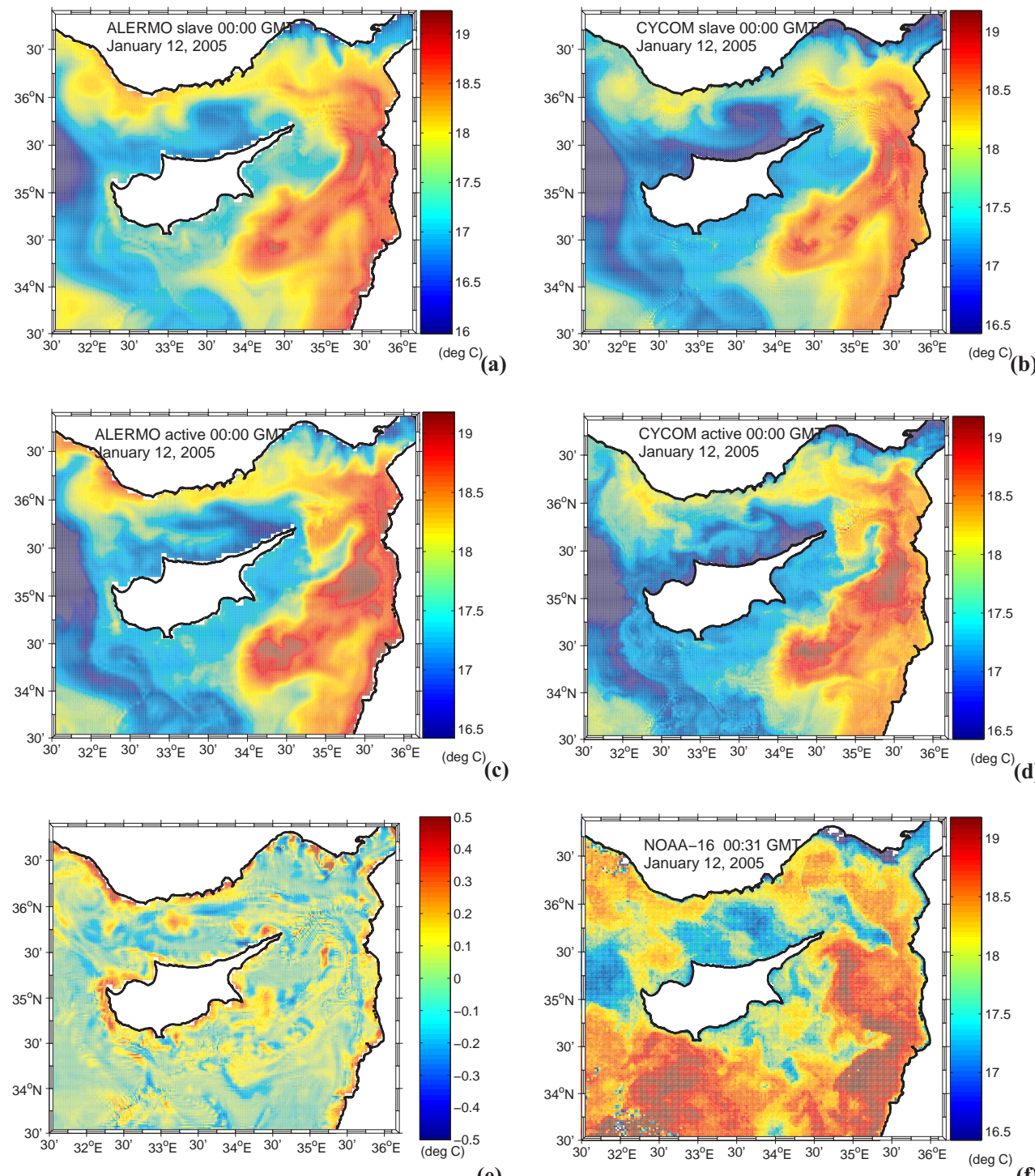

(e)

Fig. 4. Sea surface temperature comparison for day 12 of active-slave experiment. (a) ALERMO slave. (b) CYCOM slave. (c) ALERMO active. (d) CYCOM active. (e) Difference between ALERMO slave and CYCOM slave. (f) Remotely-sensed image for the same day. ALERMO figures are 24-h averages, while CYCOM images are 6-h averages.

The ALERMO model covers the geographical area $20^{\circ} \mathrm{E}-$ $36.4^{\circ} \mathrm{E}, 30.7^{\circ} \mathrm{N}-41.2^{\circ} \mathrm{N}$ and has one open boundary located at $20^{\circ} \mathrm{E}$ as shown in Fig. 1. The computational grid has a horizontal resolution of $1 / 30^{\circ} \times 1 / 30^{\circ}(493 \times 316$ grid points $)$, 25 sigma levels, and a minimum depth of $25 \mathrm{~m}$. The oneway nesting with the global Mediterranean OGCM is applied along the western boundary of ALERMO and is described in Korres and Lascaratos (2003).

\subsection{Operational mode}

During the MFSTEP project, ALERMO was initialized every Wednesday from a 24-h average field from the MFS basin model (day one of a ten-day forecast, averages centered at 00:00 UT). The first set of five daily average fields from ALERMO was centered at noon Wednesdays and was used to initialize CYCOM every Thursday. For surface forcing, the Wednesday SKIRON forecast was applied. Since CYCOM begins at noon, the first $12 \mathrm{~h}$ of the SKIRON forecast are lost, and CYCOM can run only 4.5 days. Average fields were used because they were required from all partners of the 


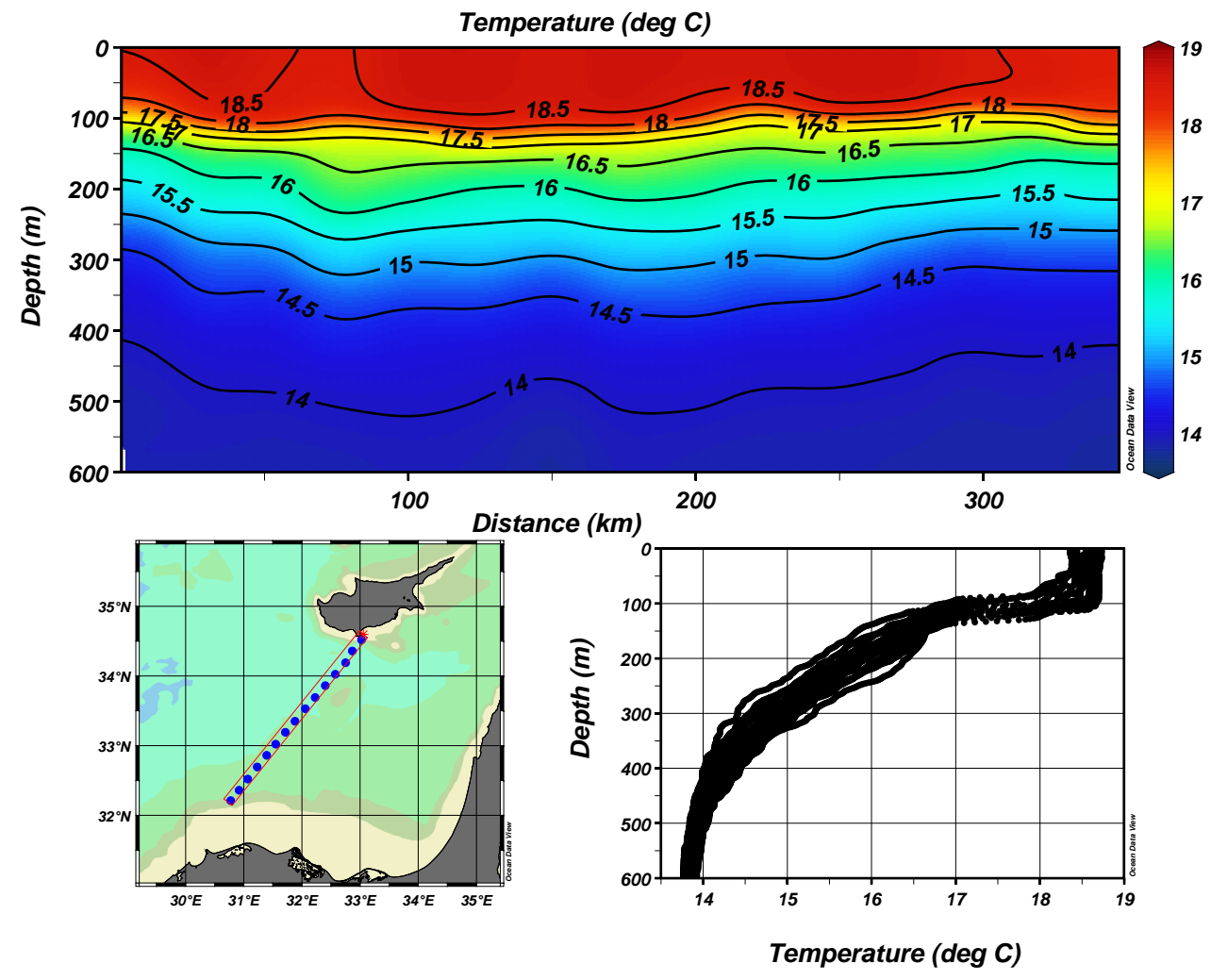

Fig. 5. Expendable bathythermograph section from 13-14 January 2005.

project for end users. Instantaneous fields could also have been used without difficulty.

A second run on Thursdays was initialized with the instantaneous fields of the first run and forced with the Thursday SKIRON forecast. Forecasts run days other than Thursday were also initialized with an instantaneous field from a previous CYCOM forecast, and applied the newly available atmospheric forecast. At the time of this study, ALERMO was running weekly, so some of the daily CYCOM forecasts used MFS basin model lateral boundary conditions. In this way, it was possible to compute 4.5 -day forecasts every day. Currently, ALERMO is running daily, and the CYCOM daily run is using the current day's SKIRON meteorological forecast and lateral boundary conditions from ALERMO.

\section{Results}

\subsection{Model-model comparisons}

\subsubsection{Downscaling from regional to coastal models}

When initializing CYCOM, it is important to maintain agreement with the basin model (and therefore ALERMO), since it has assimilation of observed data. A forecast produced on 28 September 2005 is now examined in order to com- pare the results of two methods of downscaling: bilinear interpolation and Variational Initialization (VI). During the period of 28 September to 17 October 2005, both methods were used in two parallel forecasting systems for comparison, after which the bilinear method was stopped. Average CYCOM fields of sea surface temperature centered at noon of the fourth day of the forecast, 2 October 2005 are compared with the ALERMO forecast on the same day (fifth day for that forecast) (Fig. 2). Comparison is better when the bilinear interpolation method is replaced by the VIFOP method of downscaling. The use of VIFOP reduces errors when an interpolated velocity interacts with high-resolution coastal features not present in the lower resolution model. Most importantly, using VIFOP improves flow direction and strength in many cases. Flow into the coast is less common. Errors in surface temperature are also seen when using bilinear interpolation. The surface temperature field produced by ALERMO (Fig. 2a) and CYCOM using the VIFOP method (Fig. 2b) differ in small areas near the coast (Fig. 2c). In these regions, the models differ by a few tenths of a degree Celsius up to $1^{\circ} \mathrm{C}$ for a very small number of grid points. Over the whole domain, the mean difference is $-0.0020^{\circ} \mathrm{C}$ (CYCOM slightly warmer), and the standard deviation is $0.154^{\circ} \mathrm{C}$. When bilinear interpolation is used, CYCOM differs much more from ALERMO in the regions near 

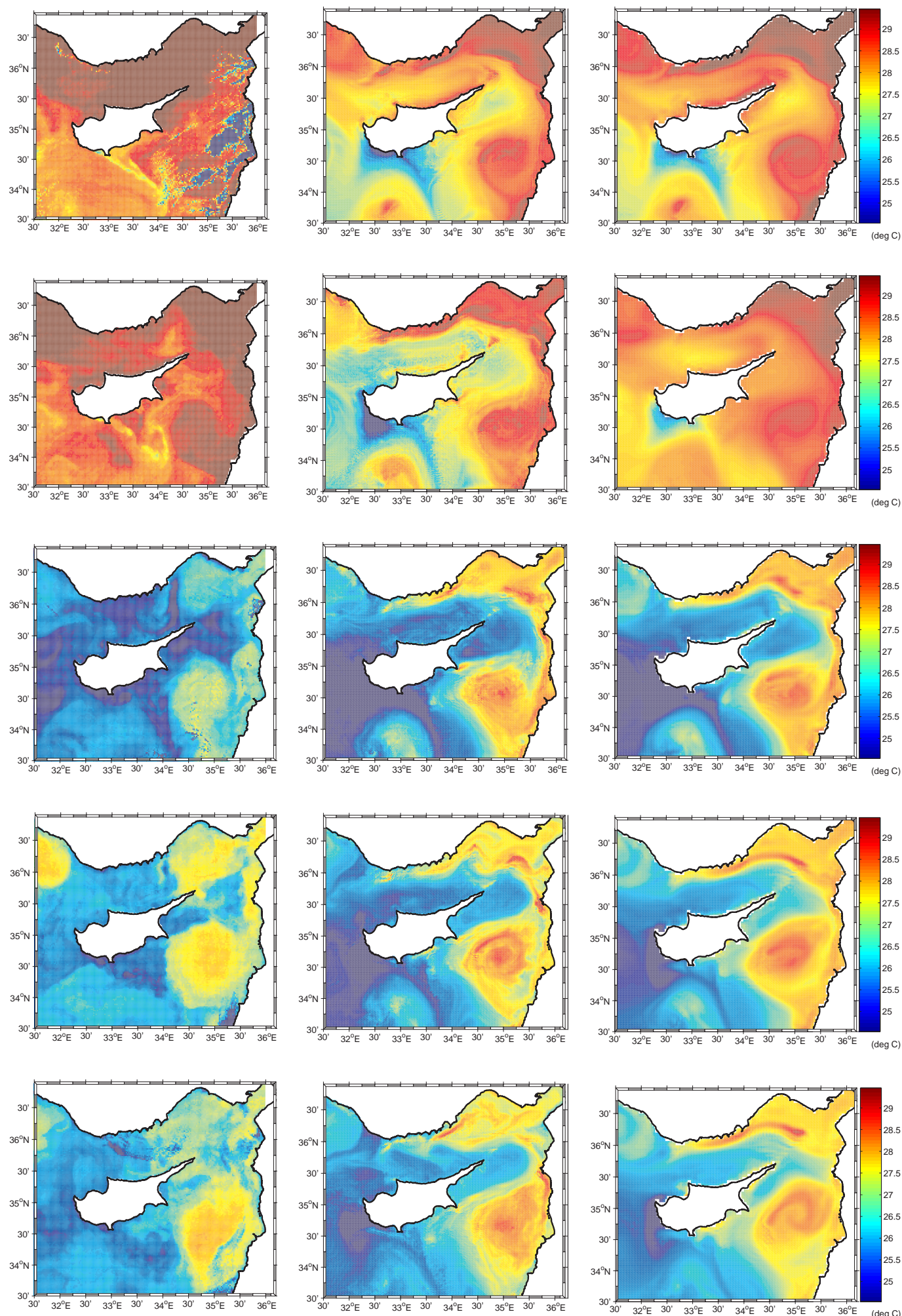

Fig. 6. SST comparison between remote-sensing, CYCOM active, ALERMO slave (from left to right). Dates are from top to bottom: 3 , 8 , 14, 20, and 28 September 2004. No correction of observed images for clouds has been made (present in 3 September image). All plots use a color scale of $24.5-29.5^{\circ} \mathrm{C}$. 

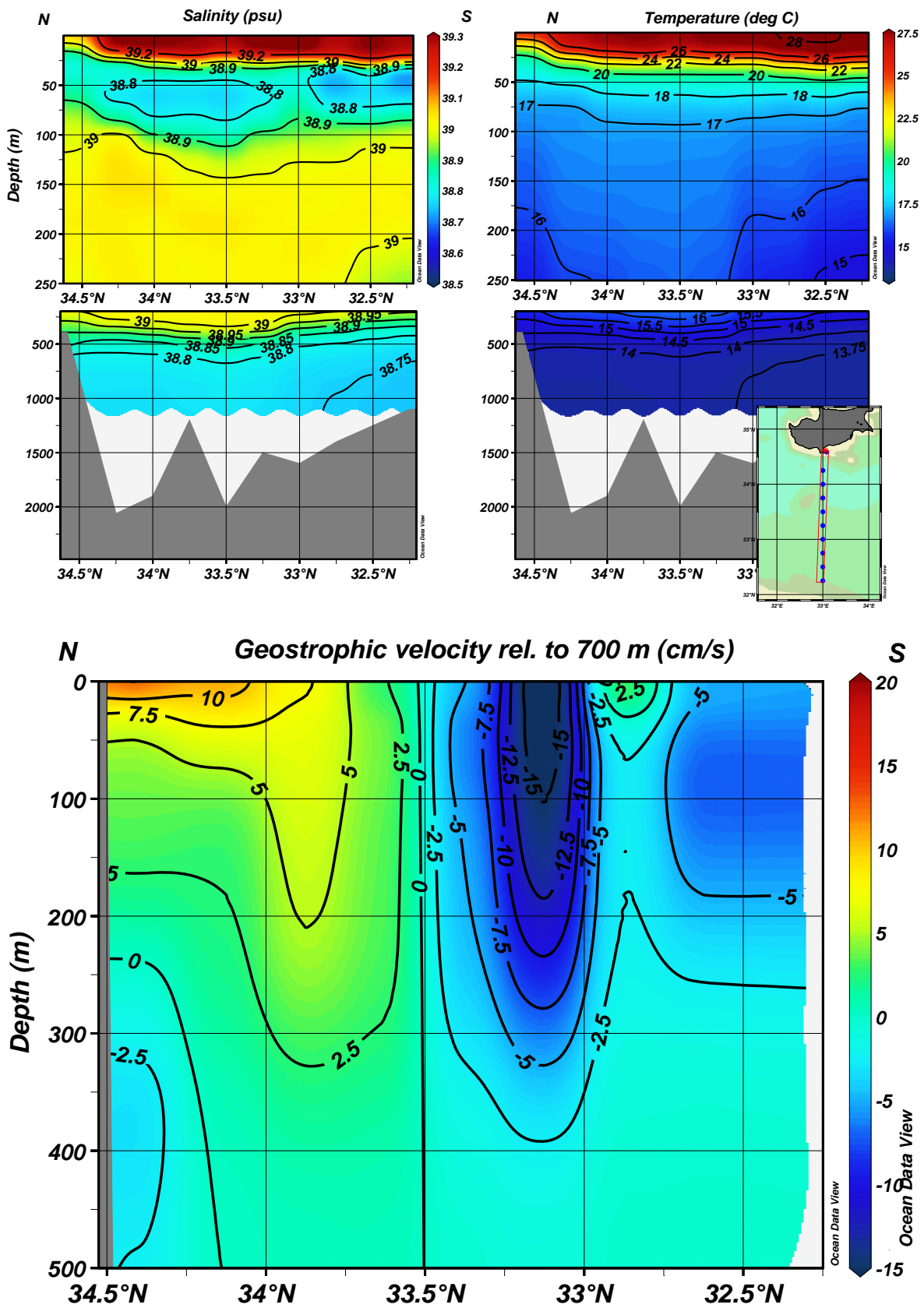

Fig. 7. (a) and (b) Hydrographic section along $33^{\circ}$ E collected during CYBO-18 (16-25 August 2004). (c) Zonal geostrophic velocity relative to $700 \mathrm{~m}$.

to the coast of Cyprus (Fig. 2d). In this case, the mean temperature difference is $-0.0357^{\circ} \mathrm{C}$ and standard deviation is $0.238^{\circ} \mathrm{C}$. Assuming a normal distribution and using the number of ALERMO ocean points in the Cyprus region (12 569), the difference field is not distinguishable from zero at the $95 \%$ confidence level when using VIFOP. When using bilinear interpolation, the bias is significant.

\subsubsection{Slave-active comparisons}

Experiments have been performed in order to investigate the effect of initialization of a model nested within a coarser resolution model. As in the operational mode, in the "slave" mode, the high resolution model, CYCOM, is initialized every week from the coarse resolution model (ALERMO) using VIFOP. The dynamical features that develop over this period are compared to those of an experiment with the same boundary and initial conditions, but with four weeks of integration without initialization ("active" mode). These experiments 

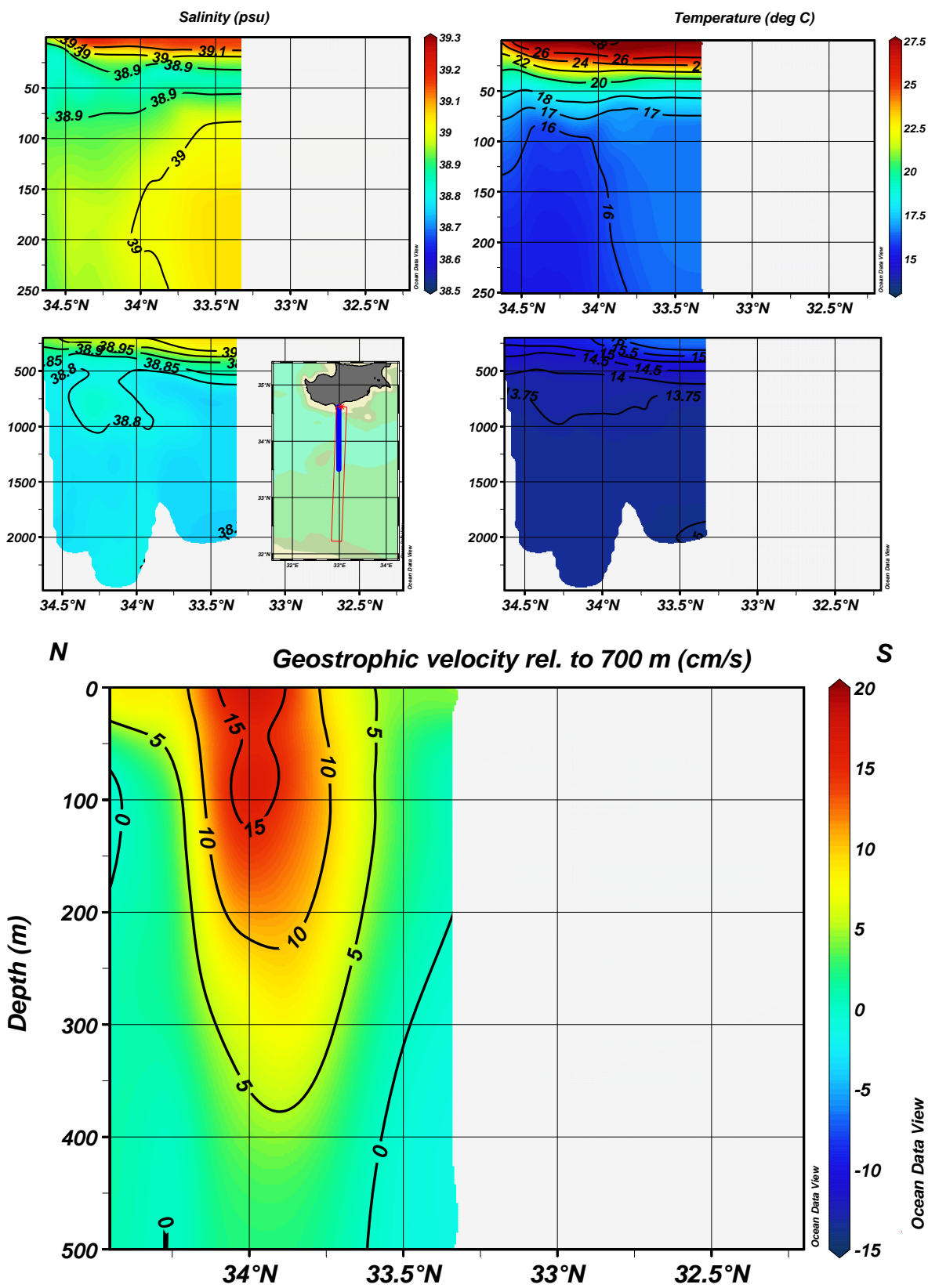

Fig. 8. Same section as Fig. 7, but from 21 August 2004 active CYCOM forecast. Note model domain extends south only to $33.5^{\circ}$ N.

have been performed at the regional and subregional scales (Sofianos et al., 2006). The goal is not to determine which model is "better" but if a more realistic forecast can be produced by initializing less frequently. Two periods were chosen to represent summer and winter: September, 2004, and January, 2005, respectively. The active runs were run for both periods and the slave only for January, 2005. Note that, aside from using analysis rather than forecast atmospheric forcing and nesting within the similarly-forced ALERMO runs, the slave and operational model simulations are set up identically.
The RMS differences in temperature, salinity, and velocity, as well as bias in temperature between the two active runs grow steadily in the January 2005 experiment. The RMS of the surface temperature difference field increases over the four weeks to $0.3^{\circ} \mathrm{C}$ (green line, Fig. 3). The same pattern is present for surface salinity and velocity components at $0 \mathrm{~m}$ and $30 \mathrm{~m}$, with $30 \mathrm{~m}$ variability slightly lower than $0 \mathrm{~m}$ (not shown). The slave run only reaches an RMS surface temperature difference of $0.13^{\circ} \mathrm{C}$ just before each weekly initialization. The mean temperature bias between the two active runs increases over the four weeks: CYCOM is cooling relative 
to ALERMO (Sofianos et al., 2006). The difference reaches $0.12^{\circ} \mathrm{C}$. For the slave mode runs, re-initialization causes a sudden cooling of slave relative to active which is larger overall than the slow relative warming of the slave between initializations (not shown). Biases in salinity and velocity are not evident.

\subsection{Model-observations comparison}

\subsubsection{Active-slave and remote sensing}

The active CYCOM run from January, 2005, is now compared to remotely-observed sea surface temperature. Images of SST of the Levantine Basin are collected by the University of Cyprus Oceanography Center's HRPT ground receiving station for the NOAA-AVHRR satellite system. Images have a spatial resolution of about $1 \mathrm{~km}$. A SmarTrack software for stand-alone data reception is used, while for the processing of the raw IR data an integrated software package specifically developed by the CYCOFOS collaborators is in use for auto mode rectification (geometric correction) of the images and the computations of the SST. The computation of the SST is based on the algorithms recommended by NOAA, using IR channels 4 and 5 . The system is set up to receive data only from night or early morning satellites passages in order to avoid the hot spots that appear during daily SST images of the Levantine Basin most of the year.

An SST image collected on 12 January 2005, 00:30 UT is compared with the active and slave runs for January 2005 in Fig. 4. The SST of the two ALERMO runs (slave and active) are shown on the left column, and the two CYCOM runs on the right hand side. Firstly, all model runs have a similar structure and temperature range, with varying degrees of small-scale variability in the form of fronts and instabilities. Note that all panels use the same temperature scale. The gross similarity is due to the inheritance of all fields from the MFS basin model. Secondly, it is clear that the two active runs have more small scale structure than their corresponding slave runs, and the two CYCOM runs (6-h averages), being at higher resolution and using shorter temporal average, have more small scale structure than the ALERMO runs (24-h averages). In turn, ALERMO has more small scale structure than the basin model, so that at each nesting level, the models have more local structure, particularly near the coast (Sofianos et al., 2006). The spatial nature of the differences between active-active and active-slave model runs consists of regions of order 10 to $100 \mathrm{~km}$ in size with differences of the order of $\pm 0.5^{\circ} \mathrm{C}$ (not shown). However, the temperature difference field of ALERMO slave minus CYCOM slave (Fig. 4e) contains similarly-sized errors in a narrow zone adjacent to all coastlines. The interior differences are much less. The same behavior is seen in $30 \mathrm{~m}$ temperature, but no corresponding zone exists for surface salinity or velocity at surface or $30 \mathrm{~m}$. It is likely that the reinitialization
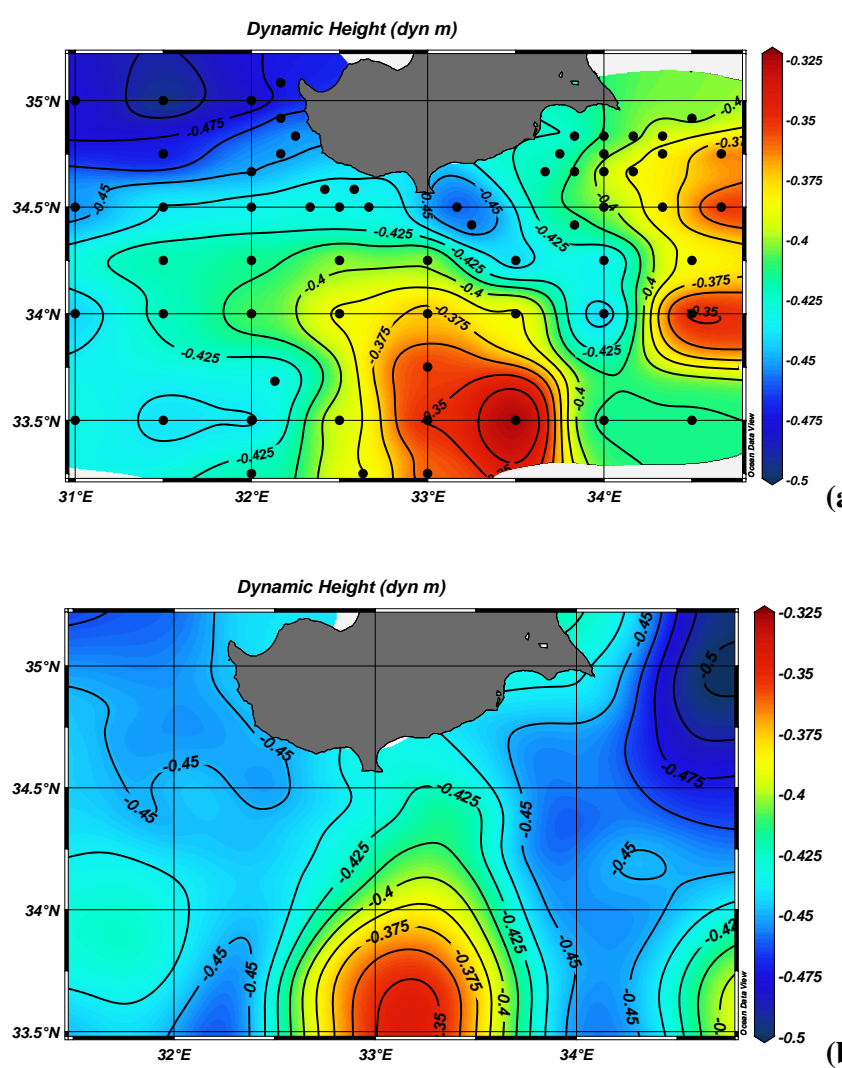

Fig. 9. Dynamic height at surface relative to $700 \mathrm{~m}$ for: (a) CYBO18. (b) Active CYCOM run averaged over 16-25 August 2004 (CYBO-18 period).

introduces this difference, which is "forgotten" by the system after a sufficient time of "active" simulation time.

The remotely-sensed image (Fig. 4f), essentially instantaneous, has many similarities with the large scale structure of the model runs: a cool pool west of Cyprus (the eastern edge of the Rhodes Gyre), a warm northward current along the Syrian coast which seems to continue into the northern Cilician basin as the Asia Minor current, and a relatively warm anticyclonic eddy east of Cyprus (although with slightly different locations). However, the models indicate a branch of cool water from the Rhodes Gyre passing SW of Cyprus (entering the domain at $34^{\circ}$ to $35^{\circ} \mathrm{N}$ and exiting at $32.5^{\circ}$ to $34^{\circ} \mathrm{E}$ ), whereas the NOAA image shows a large patch of warm water in this region. An XBT transect from this period shows a slightly cooler surface SW of Cyprus (Fig. 5). In the XBT transect, there is a change from 18.8 to $18.4^{\circ}$ covering a distance of about $20 \mathrm{~km}$ in the region, which is not evident in the NOAA image and is slightly less than the change in temperature seen in the model field in this region. Other SST images during January (of which there are few clear sky images) are similar to the one shown here. Both XBT and SST data were used by the MFS basin model (but not ALERMO) for assimilation (XBT) or surface flux corrections (SST), and the analyses fields of the basin model 

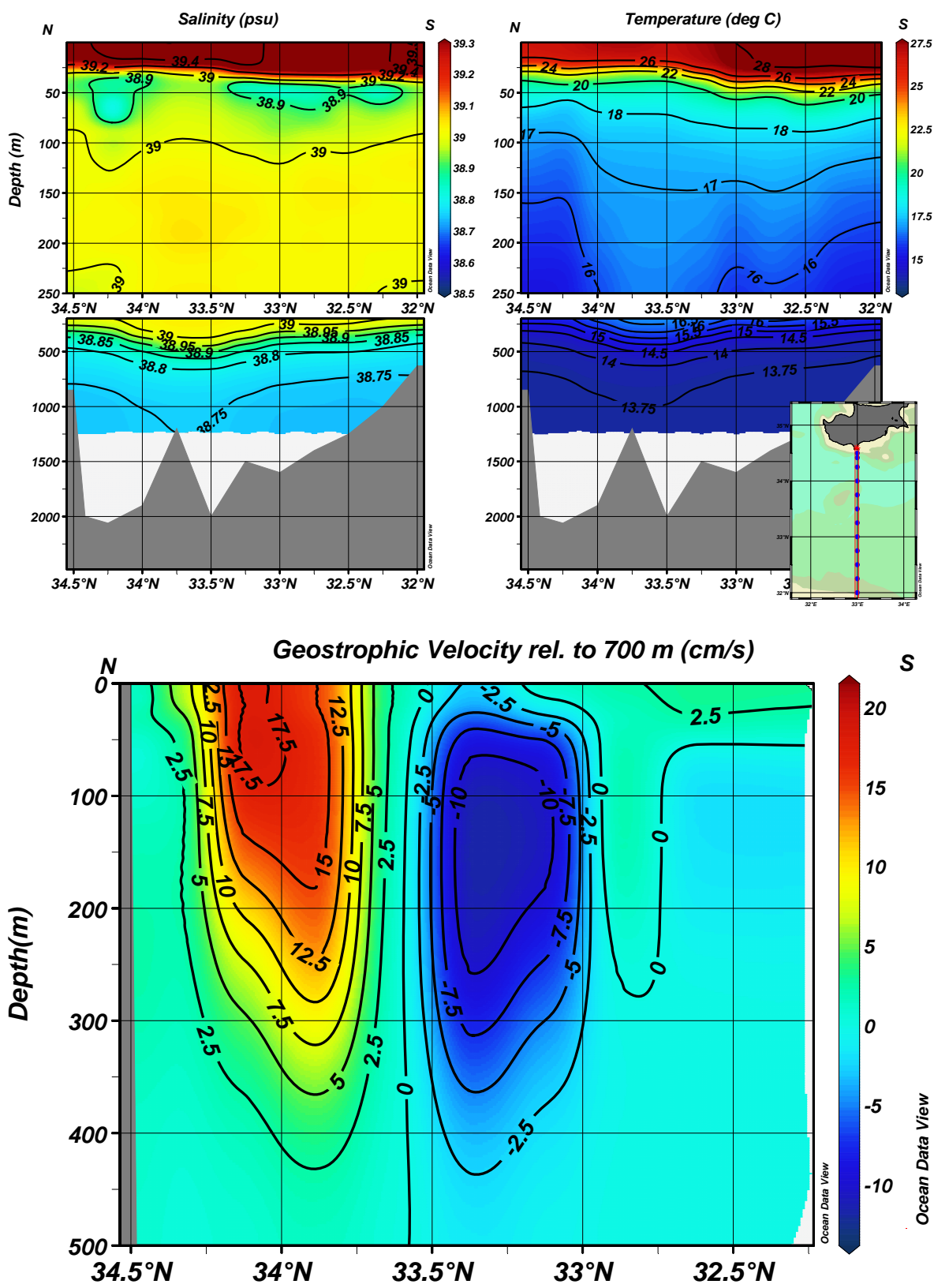

Fig. 10. Same section as in Fig. 7, but for CYBO-19 (9 to 19 September 2005).

indicate a reduction in the strength of the model cool current relative to the forecast field (not shown). It appears the assimilation of XBT data dominated the effect of correcting surface heat fluxes, and thus maintained the cooler surface waters SW of Cyprus.

In contrast, the active CYCOM run of September, 2004 agrees qualitatively with the remotely-sensed SST images available (Fig. 6). 3, 8, 14, 20 September and 28 are each represented by a row of images; the first image is the remotelysensed SST from the NOAA AVHRR system. The second column is the active CYCOM 6-h average closest to the time of the satellite observation. Also shown are the correspond- ing 24-h average ALERMO slave fields. The main features of the observed fields are present in the forecast fields: a large anticyclone southeast of Cyprus, warm water along the eastern and northern coasts of the Levantine, cooler waters off the south coast of Turkey and around the southern and western coast of Cyprus. The latter cooler waters are most likely due to a combination of upwelling and advection from the Rhodes Gyre, both observed in this region. The region west and south of Cyprus is cooler in the forecasts than in observations. In the near-coastal areas south and east of Cyprus, the active CYCOM model is in slightly better agreement with observations than is the slave run of ALERMO (similar to the 
operational slave run of CYCOM, not shown here). While the CYCOM active run appears to contain smaller scale features than the coarse slave model and therefore be more realistic, it is informative to calculate the bias and root-meansquare differences over the basin between the observations and each model. See Table 1. The rms differences are nearly the same for both models. For four of the five cases, the CYCOM mean is closer to observations, while for the other ALERMO active is closer. All means are significant at the 95\% level. It is difficult to conclude quantitatively, then, that one model is "better" than the other, but we can conclude that the one month active mode of running is as good or better than the one week slave mode. It is significant that the mean difference between observed and active run surface temperatures does not grow over time.

\subsubsection{Active run and in situ data, August 2004}

Intensive annual or semi-annual hydrographic cruises south of Cyprus have been carried out since 1995, and they enable model validation at a high level of detail. The cruises are part of the Cyprus Basin Oceanography (CYBO) program of the Oceanography Centre. Data are collected with an SBE 911+ system, which is calibrated on an annual basis. Downcast data were processed first by manual removal of the initial thermal adjustment period and spikes. Next pressure, temperature, and salinity were low-pass filtered with time constants of $0.15,0.5$, and $1.0 \mathrm{~s}$, respectively. The data discussed here were collected during the period of 16-25 August 2004, (cruise CYBO-18). A special experiment was performed in which CYCOM was nested directly within the MFS-basin model (Pinardi, 2003) using the analysis output of August 2004. This active mode experiment was initialized 1 August 2004, and used MFS-basin model lateral and surface forcing. The MFS-basin model meteorological forcing comes from ECMWF.

Two vertical temperature sections and dynamic height from observations and the model experiment are compared here. The north-south vertical section of in situ measurements along $33^{\circ} \mathrm{E}$ (Fig. 7) indicates clearly the warm, salty summertime mixed layer down to $30 \mathrm{~m}$, the influence of Atlantic Water (AW) from $30 \mathrm{~m}$ down to $100 \mathrm{~m}$, the Levantine Intermediate Water (LIW) from $100 \mathrm{~m}$ to $500 \mathrm{~m}$, and the Eastern Mediterranean Deep Water (EMDW) below $500 \mathrm{~m}$. The low salinity $(<38.9 \mathrm{psu})$ AW is known to traverse the Levantine basin in the form of a meandering jet: the MidMediterranean Jet (MMJ) (Zodiatis et al., 2005). The corresponding geostrophic velocity perpendicular to the section presents a strong reversal in flow direction: eastward velocity north of $33.5^{\circ} \mathrm{N}$ and westward velocity south of this location (Fig. 7c). The active forecast from 21 August 2004, the day of the observed transect, shows the same overall situation, although the model domain extends no farther south than $33.5^{\circ} \mathrm{N}$ (Fig. 8). Absolute values of temperature and salinity are close to observations; at any given depth forecast tem-
Table 1. Mean and standard deviation of difference between remotely-sensed sea surface temperature $\left(\mathrm{T}_{\mathrm{REM}}\right)$ and either $\mathrm{CY}$ COM active forecast $\left(\mathrm{T}_{\mathrm{CY}}\right)$ or ALERMO slave forecast $\left(\mathrm{T}_{\mathrm{AL}}\right)$. Five dates in September were analyzed (see Fig. 6 for temperature fields). The number of ocean points for CYCOM is 41939 , for ALERMO is 12569 and for remote sensing is 77128 .

\begin{tabular}{ccccc}
\hline $\begin{array}{c}\text { Day of } \\
\text { Sep. 2005 }\end{array}$ & \multicolumn{2}{c}{$\begin{array}{c}\mathrm{T}_{\mathrm{REM}}-\mathrm{T}_{\mathrm{CY}} \\
\left({ }^{\circ} \mathrm{C}\right)\end{array}$} & \multicolumn{2}{c}{$\begin{array}{c}\mathrm{T}_{\mathrm{REM}}-\mathrm{T}_{\mathrm{AL}} \\
\left({ }^{\circ} \mathrm{C}\right)\end{array}$} \\
& STD & MEAN & STD & MEAN \\
\hline 3 & 1.7 & 0.38 & 1.8 & 0.64 \\
8 & 0.44 & 0.60 & 0.75 & 1.3 \\
14 & 0.96 & -0.57 & 1.0 & -0.35 \\
20 & 0.89 & -0.11 & 0.95 & 0.20 \\
28 & 0.59 & -0.30 & 0.64 & -0.53 \\
\hline
\end{tabular}

perature is generally within $1{ }^{\circ} \mathrm{C}$ of observations, and forecast salinity is within $0.1 \mathrm{psu}$ of observations. Note that the same color scales are used throughout. The high salinity and temperature surface layer is present, but slightly less sharply defined. The surface layer in the model is fresher, shallower, and slightly warmer. The Atlantic Water signature is evident but weaker, and LIW is present but less saline in the north part of the section. The model predicted the northern half of the geostrophic velocity dipole, the southern half being out of its domain (Fig. 8c). However, the current speeds are much higher than calculated from observations.

The dynamic height relative to $700 \mathrm{~m}$ for CYBO-18 presents strong evidence for the presence of a barotropic jet south of Cyprus (Fig. 9a). The jet enters the domain from the south, between $32^{\circ} \mathrm{E}$ and $33^{\circ} \mathrm{E}$, makes an anticyclonic loop and exits the domain. The jet appears to bifurcate near $33.75^{\circ} \mathrm{N}$ and $34^{\circ} \mathrm{E}$, with some flow southward out of the domain and some northward along the edge of another anticyclonic feature visible at the eastern edge of the domain. A weaker current enters the domain from the west around $34.5^{\circ} \mathrm{N}$, bifurcates west of Cyprus, and the southern branch joins the current system discussed above. The CYCOM active forecast averaged over the cruise period (16-25 August 2004) indicates elevated sea surface height in the region south of Cyprus, a region of known anticyclonic activity (Fig. 9b). The anticyclonic feature southeast of Cyprus is further south and weaker in the forecast and in its place is strong cyclonic gyre not present in the cruise data. Note the contour intervals are the same, as are the full scale ranges. 

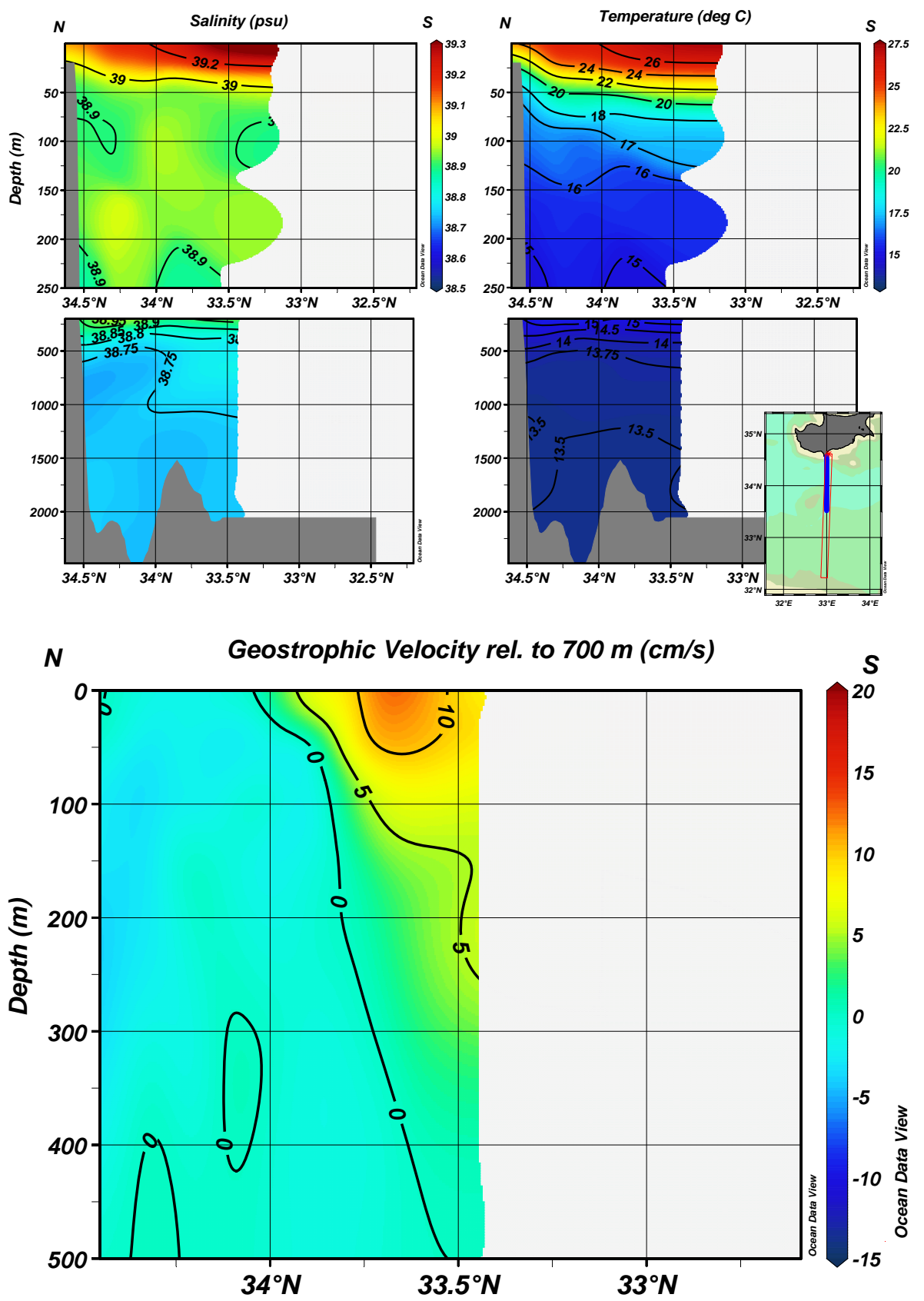

Fig. 11. Same section as Fig. 7, but from 9 September 2005 operational CYCOM forecast (day four of that forecast, 13 September).

\subsubsection{Operational run and in situ data, September 2005}

Hydrographic data from CYBO-19 (9 to 19 September 2005) are now compared with the operational CYCOM forecasts of September, 2005. The hydrographic data for the northsouth section along the $33^{\circ} \mathrm{E}$ meridian again indicate the influence of Atlantic Water from 34.0 to $34.4^{\circ} \mathrm{N}$, and at depths between $30 \mathrm{~m}$ and $90 \mathrm{~m}$ (Fig. 10a). The AW signal is weaker than observed in 2004. The summertime surface layer (slightly deeper than in 2004), LIW, and EMDW are all present. As in 2004, the surface layer deepens and warms from north to south (Fig. 10b). Much like CYBO-18, a dipole in zonal geostrophic velocity relative to $700 \mathrm{~m}$ is centered at $33.6^{\circ} \mathrm{N}$ and extends from the surface down to $300 \mathrm{~m}$ (Fig. 10c). Compared to the observations, the model forecast section from the 13 September daily average contains a weaker and deeper low salinity core in the northern part (Fig. 11a). Differences in the sharpness of the thermocline and halocline are evident, the forecast indicating weaker stratification, as in 2004. Also, the surface layer deepens in the model from north to south, but not in the observations (for the region in the model domain: north of $33.5^{\circ} \mathrm{N}$ ). 

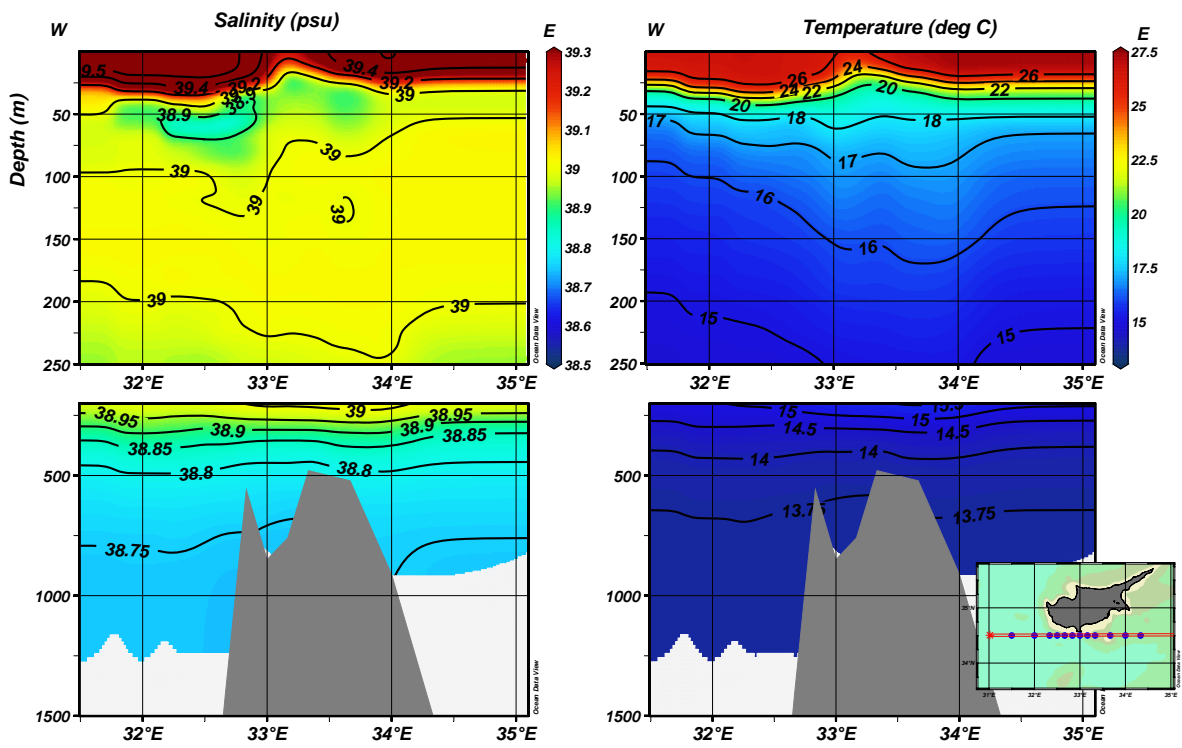

Fig. 12. Hydrographic section along $34.5^{\circ} \mathrm{N}$ collected during CYBO-19 (9 to 19 September 2005).
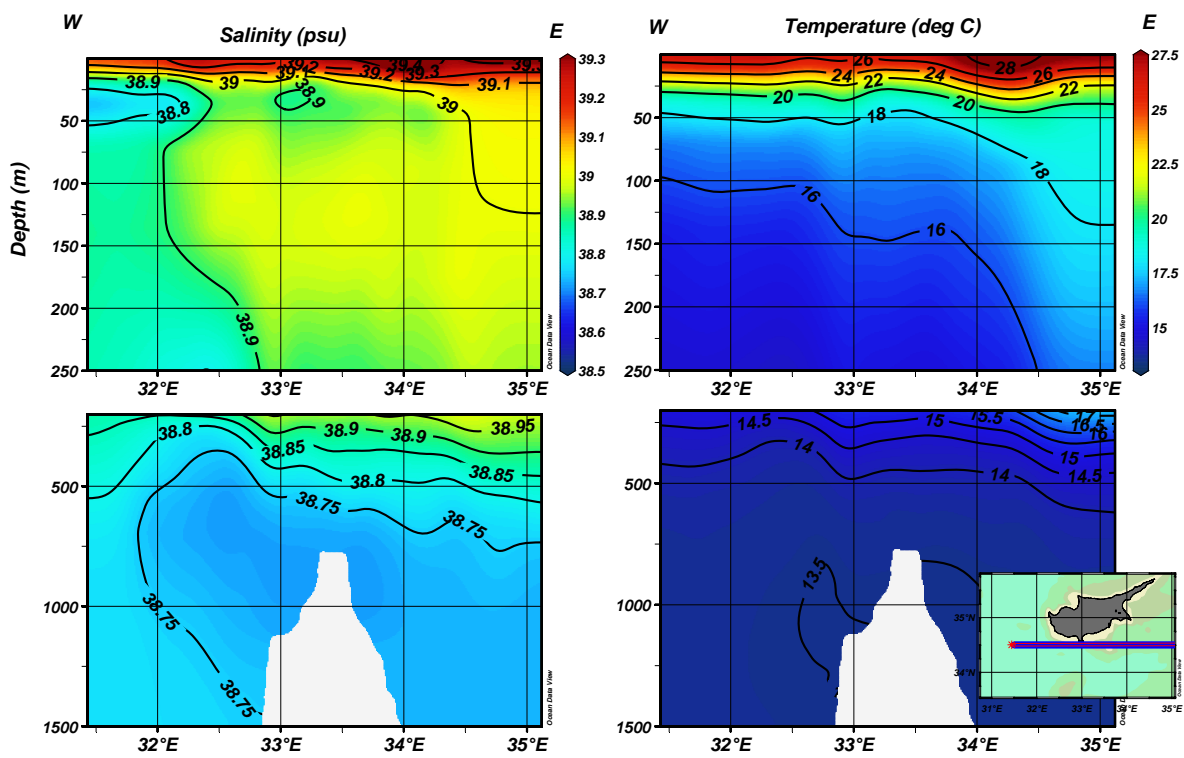

Fig. 13. Same section as Fig. 12, but from average of 7-17 September 2005 CYCOM operational forecast (day 3 from each which covers CYBO-19 period).

As in 2004, the LIW is slightly fresher in the model. The geostrophic velocity section does not indicate a dipole, but a weaker, more shallow eastward flow north of $33.5^{\circ} \mathrm{N}$. It should be noted once again that the model domain does not extend south of this point, where the westward geostrophic flow was indicated by CYBO-18 and CYBO-19 observations. An east-west section for CYBO-19 along $34.5^{\circ} \mathrm{N}$ shows evidence of the AW (Fig. 12a). Between 33 and $34^{\circ} \mathrm{E}$, however, where the bathymetry is relatively shallow, the AW signal is weak, and the surface layer is very thin. The eastwest section of forecast data (averaged over the sampling period of the CYBO-19 section) indicates AW is present in the west but shifted west of $32^{\circ} \mathrm{E}$ and the surface layer is present but shallower and fresher (Fig. 13). The intermediate depths are approximately $0.1 \mathrm{psu}$ fresher in the forecast, and there is generally more horizontal variability visible in the forecast. Note that this variability is beyond the resolution of the observations.

Dynamic topography from observations and the forecast (Fig. 14) for September 2005 again suggest an anticyclonic circulation south of Cyprus. However, this time the region is much larger and the implied geostrophic zonal current weaker. The anticyclone in the model is much weaker and slightly south and west of the observed location. Both 


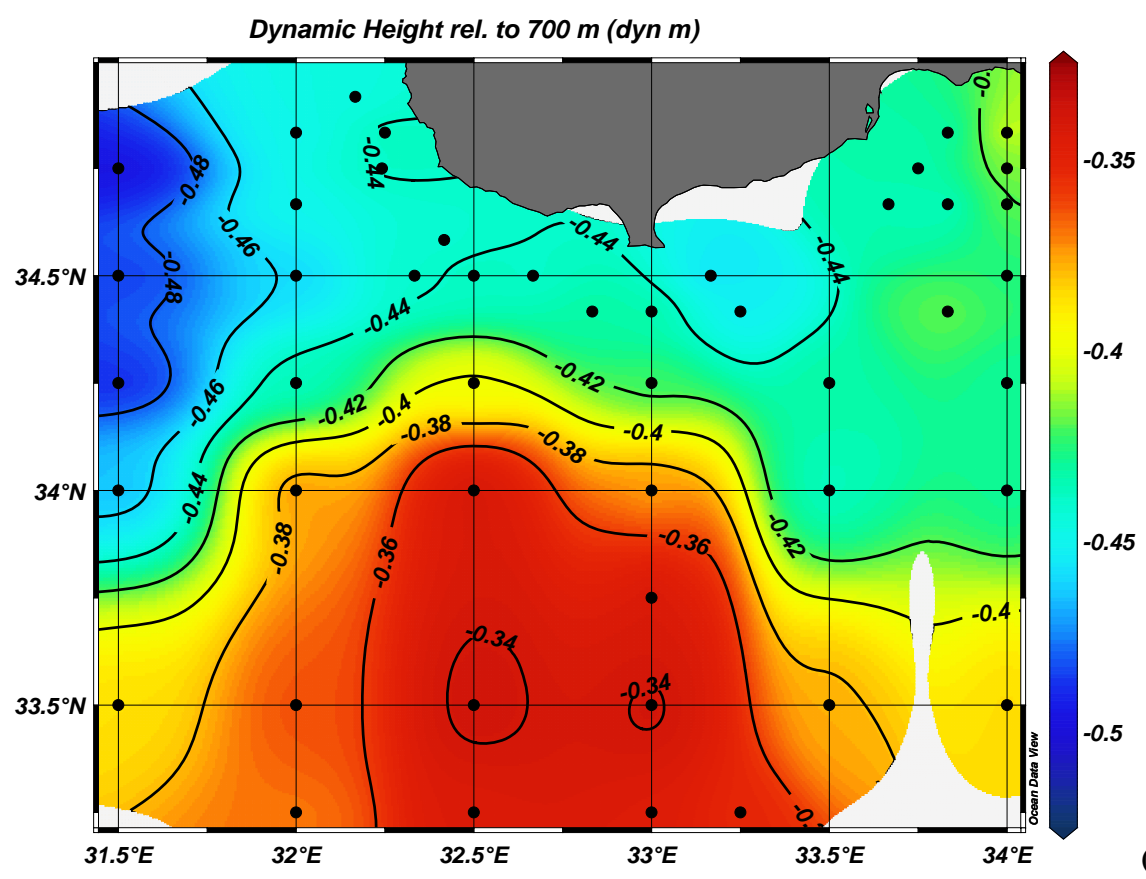

(a)

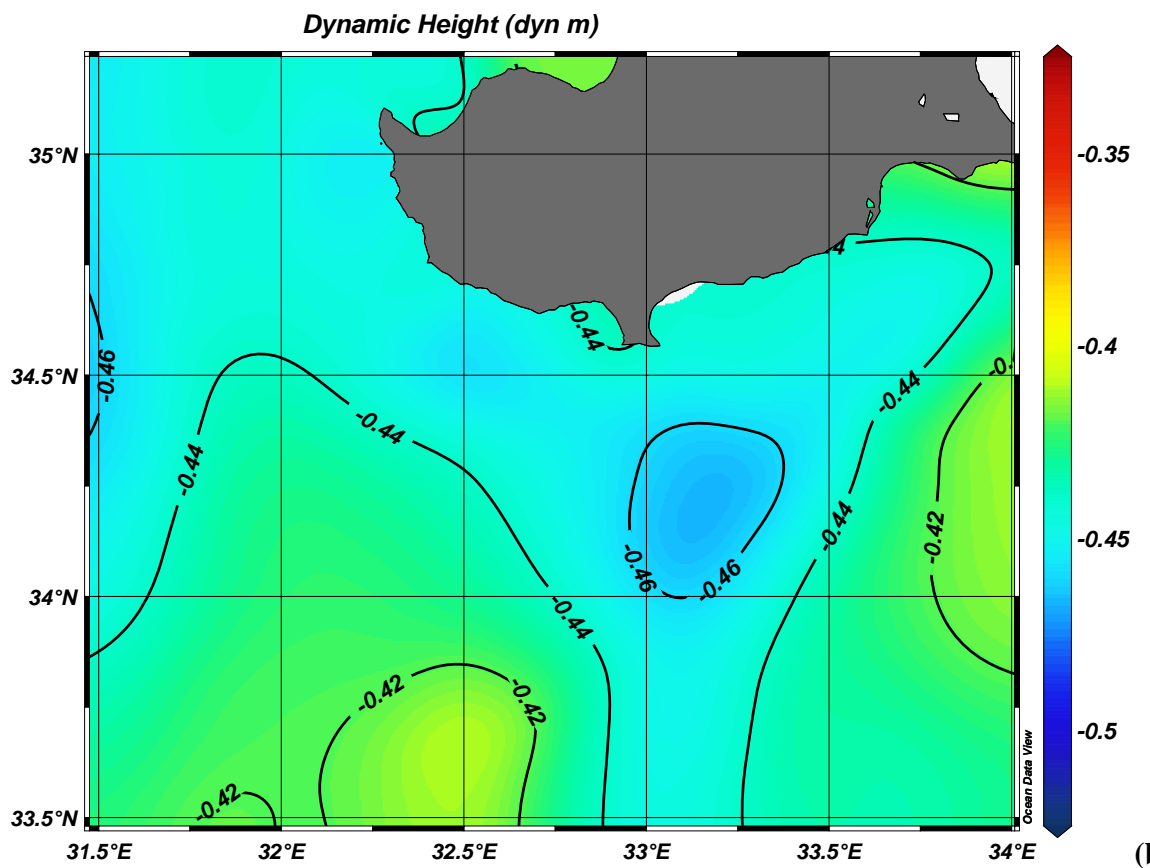

(b)

Fig. 14. Dynamic height at surface relative to $700 \mathrm{~m}$ for: (a) CYBO-19. (b) Active CYCOM run (day 3 outputs) averaged over CYBO-19 period.

forecast and observations show the edge of a cyclonic region west of Cyprus and regions of low sea surface height around the south coast. The major difference between the two is near the eastern edge of the domain where the model indicates increasing sea surface height (a secondary anticyclone) while the data do not.

\subsubsection{Operational run and in situ data, July 2006}

A coastal cruise carried out on 12 July 2006 collected water velocity profiles near the south coast of Cyprus using an Acoustic Doppler Current Profiler (ADCP). An RDI $300 \mathrm{KHz}$ Workhorse Sentinel was deployed over the side of a small boat one meter below the surface. One minute ensembles, each containing 37 water pings were collected, and five ensembles were averaged for each station. Vertical bins 


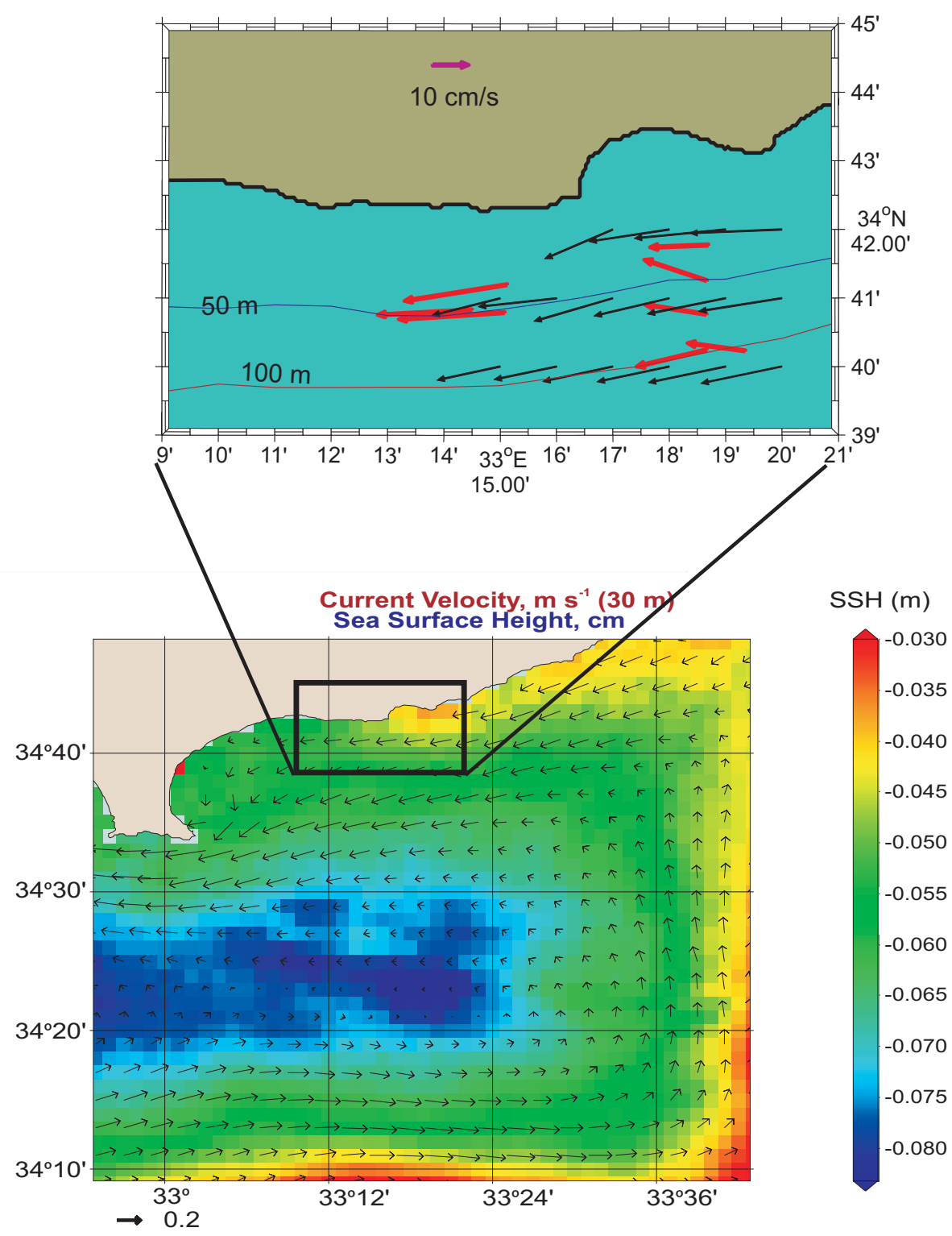

Fig. 15. Daily average sea surface height (shading) and current velocity field at $30 \mathrm{~m}$ on 12 July 2006 from day one output of July 11 operational CYCOM forecast. Inset shows a zoom of forecast velocities overlaid with ADCP-observed $30 \mathrm{~m}$ velocity vectors.

were three meters thick, and velocity was referenced to the bottom track velocity. Water depth at each of the stations did not exceed $100 \mathrm{~m}$. Weather conditions during the experiment consisted of clear skies and no wind, until a sea breeze began near the end of the experiment. For 12 July, the operational forecast indicated a cyclonic circulation at $30 \mathrm{~m}$ in the open sea south of Cyprus (Fig. 15). The barotropic flow field that would be surmised from the geostrophy of sea surface height (color shading) indicates a similar flow pattern. In the experimental area, this resulted in a nearly due westward flow of about $0.20 \mathrm{~m} \mathrm{~s}^{-1}$ peaking between $10 \mathrm{~m}$ and $20 \mathrm{~m}$, with decreases to near zero values at the surface and at depth. The ADCP profiles on the morning of 12 July agree with the day's average forecast currents in direction and are larger in magnitude by about $0.10 \mathrm{~m} \mathrm{~s}^{-1}$ in the $10 \mathrm{~m}$ to $30 \mathrm{~m}$ depth range. The $30 \mathrm{~m}$ velocities show similar directions and slightly larger magnitudes (Fig. 15). The open sea circulation has a strong influence on near coastal circulation.

\section{Conclusions}

An ocean forecasting system for the waters surrounding Cyprus and the Levantine basin is fully operational and producing good results. Through the internet, it provides forecasts of ocean flow, temperature, and salinity (daily and 6-h 
average fields are computed for the coming five days, every day). The Cyprus coastal flow model, CYCOM, is initialized from the regional ALERMO model, using a variational initialization method (VIFOP). In this configuration, the daily CYCOM forecast is shown to be in especially good agreement with the regional forecast on large scales, with most differences being small, near the coast, and/or beyond the resolution of ALERMO. Twin 28-day numerical experiments have been carried out where in one CYCOM is initialized every week from the coarse model (slave), and in the other initialized only at the beginning (active). Results indicate that the root-mean-square difference between the active and slave modes for CYCOM (near the surface and for all variables) increases quickly in the first 14 days, but then grows more slowly. Simulated and remotely-sensed sea surface temperature show a qualitatively better agreement for the active runs due to the finer scale structures present (and illustrate the need for improved data assimilation in some regions and seasons). The differences between active or slave mean model temperatures from the mean remote sensing observations do not grow over a month of simulation. We feel that the operational results of the forecasting system would benefit from a longer "active" period, perhaps two weeks instead of one. The potential drawback of unrealistic model fields appears to be insignificant, and the simulated (and realistic) increase in small-scale features is desired. Another benefit of longer active run simulations is the decrease in differences in temperature near the coast, seen in slave-slave comparisons even five days after initialization. Comparable results are found in forecasts (both active and operational) and in situ hydrographic data for 2004 and 2005. Both forecast and observations show the presence of relatively fresh Atlantic Water, plus the other characteristic water masses of the region. Geostrophic calculations for both numerical and observational data show generally eastward flowing near-surface currents encircling an anticyclone south of Cyprus and cyclonic circulations west and southeast of Cyprus, in agreement with previous field studies (Zodiatis et al., 2004, 2005) and climatological numerical studies (Zodiatis et al., 2003).

By using a high resolution model, end-user applications are often more reliable. For example, when the forecast currents are used in an oil-spill model to predict the fate of a near-coast spill, basin and regional models are often insufficient in resolution. More accurate results are obtained from coastal models like CYCOM, because of resolution of coastline and bathymetry, and small scale wind and current and temperature features. It is true that localized features visible in remotely-sensed sea surface temperature are not simulated extremely well, but it should be noted that the images are essentially instantaneous, while model output shown here were six-hourly averages. Also, the assimilation of sea surface temperature (done at the basin scale model, carried through ALERMO to CYCOM slave runs) is based on composite fields, which are generally smoother than instantaneous images. Finally, even with a perfectly initialized model state, the physical system is too complex to expect accurate predictions of individual temperature filaments and plumes after a week or more of running.

CYCOM will be developed further by implementing assimilation of local observations such as expendable bathythermographs (XBTs), conductivity-temperature-depth (CTD) profiles from drifters and gliders, and CT data from the CYCOFOS ocean observatory. Assimilation will be particularly useful for improving forecast skill of open sea fronts and mesoscale activity, from the surface to the depth extent of the measurements (no more than $1000 \mathrm{~m}$ ). Because of the tight relation between near coast and open sea features near Cyprus, forecast skill for coastal conditions will be indirectly improved. Sea level anomaly can also be assimilated at times when satellite altimeter tracks are available in our region. Another, simpler, possibility for model improvement would be a relaxation to the coarse model, rather than initialization, therefore keeping some locally-generated features.

Acknowledgements. This research has been carried out in the framework of the European Union project MFSTEP, contract EVK3-CT-2002-00075. We acknowledge the support of the CYCOFOS collaborators: E. Demirov, Z. Di Bennardo, T. Eleftheriou, M. Papaioannou, S. Savva, and D. Soloviev. Figures 5, 7-14 have been whole or partially generated with Ocean Data View software (Schlitzer, 2006).

Edited by: D. Webb

\section{References}

Auclair, F., Casitas, S., and Marsaleix, P.: Application of an inverse method to coastal modelling, J. Atmos. Oceanic Tech., 17, 13681391, 2000a.

Auclair, F., Marsaleix, P., and Estournel, C.: Truncation errors in coastal modelling: evaluation and reduction by an inverse method, J. Atmos. Oceanic Tech., 17, 1348-1367, $2000 \mathrm{~b}$.

Bignami, F., Marullo, S., Santoreli, R., and Schiano, M. A.: Longwave radiation budget in the Mediterranean sea, J. Geophys. Res., 100(c2), 2501-2514, 1995.

Blumberg, A. F. and Mellor, G. L.: A description of a three-dimensional coastal ocean circulation model, in: ThreeDimensional Coastal Ocean Circulation Models, Coastal Estuarine Sci., 4, edited by Heaps, N. S., AGU, Washington, D.C., 1-16, 1987.

Budyko, M. I.: Atlas of the heat balance of the earth, Glabnaia Geofizicheskaia Observatoriia, Moscow, pp. 69, 1963.

Hellerman, S. and Rosenstein, M.: Normal wind stress over the world ocean with error estimates, J. Phys. Ocean., 13, 10931104, 1983.

Kallos, G., Nickovic, S., Papadopoulos, A., Jovic, D., Kakaliagou, O., Misirlis, N., Boukas, L., Mimikou, N., Sakellaridis, G., Papageorgiou, J., Anadranistakis, E., and Manousakis, M.: The regional weather forecasting system Skiron: An overview, Proceedings of the Symposium on Regional Weather Prediction on Parallel Computer Environments, 109-122, 15-17 October 1997, Athens, Greece, 1997. 
Korres, G. and Lascaratos, A.: A one-way nested eddy resolving model of the Aegean and Levantine basins: implementation and climatological runs, Ann. Geophys., 21, 205-220, 2003, http://www.ann-geophys.net/21/205/2003/.

Lardner, R. W. and Cekirge, H. M.: A new algorithm for threedimensional tidal and storm surge computations, App. Math Model, 12, 471-571, 1988.

Lascaratos, A. and Nittis, K.: A high resolution three-dimensional numerical study of intermediate water formation in the Levantine Sea, J. Geophys. Res., 103(C9), 18 497-18 511, 1998.

Mellor, G. and Yamada, T.: Development of a turbulent closure model for geophysical fluid problems, Rev. Geophys., 20, 851875, 1982.

Pinardi, N., Allen, I., Demirov, E., De Mey, P., Korres, G., Lascaratos, A., Le Traon, P. Y., Maillard, C., Manzella, G., and Tziavos, C.: The Mediterranean ocean forecasting system: first phase of implementation (1998-2001), Ann. Geophys., 21, 3-20, 2003, http://www.ann-geophys.net/21/3/2003/.

Schlitzer, R.: Ocean Data View, http://odv.awi.de, 2006.

Smagorinsky, J.: General circulation experiments with the primitive equations. Part I: the basic experiment, Mon. Weather Rev., 91, 99-165, 1963.
Sofianos, S., Skliris, N., Mantziafou, A., Lascaratos, A., Zodiatis, G., Lardner, R., Hayes, D., and Georgiou, G.: Nesting operational forecasting models in the Eastern Mediterranean: active and slave mode, Ocean Sci. Discuss., 3, 1225-1254, 2006, http://www.ocean-sci-discuss.net/3/1225/2006/.

Spall, M. A. and Holland, W. R.: A nested primitive equation model for oceanic applications, J. Phys. Oceanogr., 21, 205-220, 1991.

Zavatarelli, M. and Mellor, G.: A numerical study of the Mediterranean sea circulation, J. Phys. Oceanogr., 25(6), 1384-1414, 1995.

Zodiatis, G., Drakopoulos, P., Brenner, S., and Groom, S.: Variability of the Cyprus warm core eddy during the CYCLOPS project, Deep Sea Res. II, 52, 2897-2910, 2005.

Zodiatis, G., Lardner, R., Lascaratos, A., Georgiou, G., Korres, G., and Syrimis, M.: High resolution nested model for the Cyprus, NE Levantine basin, eastern Mediterranean Sea: implementation and climatological runs, Ann. Geophys., 21, 221-236, 2003, http://www.ann-geophys.net/21/221/2003/.

Zodiatis, G., Drakopoulos, P., and Gertman, I.: Modified Atlantic Water in the Levantine Basin, 37th CIESM Congress Proceedings, 37, Barcelona, pp. 574, Spain, 2004. 